\title{
Mortality from Parkinson's disease in England and Wales 1921-89
}

\author{
C E Clarke
}

\begin{abstract}
Mortality from Parkinson's disease in England and Wales was re-examined using published government statistics. The $300 \%$ increase in the crude mortality rate between 1921 and 1989 was largely attributable to the increase in the elderly population who suffer a higher prevalence of the disease. The dramatic fall in 1940 and rise in 1984 were artefacts caused by changes in certification. Agespecific mortality fell after 1940 in all groups below 70 years and in both sexes, but increased in those over 75 years. Analysis by birth cohort showed a progressive decline in mortality at younger ages with successive cohorts but stable mortality in the elderly. Younger patients were probably misclassified cases of "late-onset" Parkinsonism following encephalitis lethargica who can be differentiated from older cases of idiopathic Parkinson's disease. Mortality decreased in all age groups in the 1970s but then increased in the early 1980s. This is comparable to trends in the United States and Scandinavia and suggests that the beneficial effects of levodopa delay death for several years.
\end{abstract}

$(\mathcal{F}$ Neurol Neurosurg Psychiatry 1993;56:690-693)

The progressive increase in the age of onset of Parkinson's disease in Massachusetts between 1875 and 1961 prompted Poskanzer and Schwab to conclude that the majority of cases were due to subclinical encephalitis lethargica and that the disease would "disappear as a major clinical entity by 1980 ". ${ }^{1}$ This was refuted by Duvoisin and colleagues on the basis of their data on the age of onset of the disease. ${ }^{2}$ They suggested that idiopathic Parkinson's disease, or the "paralysis agitans" of James Parkinson, ${ }^{3}$ continued to occur while post-encephalitic Parkinsonism was dying out. They went on to show that the mortality from Parkinson's disease in England and Wales had not fallen since the outbreaks of von Economo's encephalitis in the 1920 s as had been predicted. ${ }^{4}$ However, using cohort analysis of the same data,
Marmot showed that deaths from postencephalitic Parkinsonism could have continued through to the 1970 s. $^{5}$

In the present study, mortality from Parkinson's disease in England and Wales was re-evaluated to clarify the aetiological significance of the data and to compare them with recent statistics from the United States ${ }^{6}$ and Scandinavia ${ }^{689}$ which show a considerable increase in mortality in the early 1980 s.

\section{Methods}

Mortality and population statistics for England and Wales were abstracted from the Registrar General's statistical reviews (1921-1973) and the Office of Population Censuses and Surveys (OPCS) reports (1974-1989) which are published annually by HMSO, London. Parkinson's disease or paralysis agitans had been coded using the International Classification of Diseases (ICD) revision 3 under code 84(4) from 1920-30, ICD-4 by code 87 (c) from 1931-39, ICD-5 by code 87 (c) from 1940-1949, ICD-6 by code 350 from $1950-1957$, ICD-7 by code 350 from 1958-1967, ICD-8 by code 342 from 1968-1978, and ICD-9 by code 332 from 1979-1989. Deaths from Parkinson's disease were not classified separately from 1901-1920.

In 1984, the OPCS adopted the WHO rule 3 in which chronic conditions listed on the death certificate were taken as the cause of death. To allow for this, dual classification was performed for 1984 and a correction factor published (correction factor $=0.585$; mortality statistics, cause, 1984; series $\mathrm{DH} 2$; No 11). This has been applied to 1984 and all subsequent years in fig 1 .

Age-specific mortality rates were calculated for successive five year age bands over the age of 50 years, mortality below this age being negligible. These figures were then used as the source for cohort analysis. Standardisation of crude mortality rates was performed by applying the age-specific rates in each year to the population data for 1921. The calculated mortality was then divided by the true mortality in 1921 and multiplied by 100 to produce a standardised mortality ratio (SMR). 


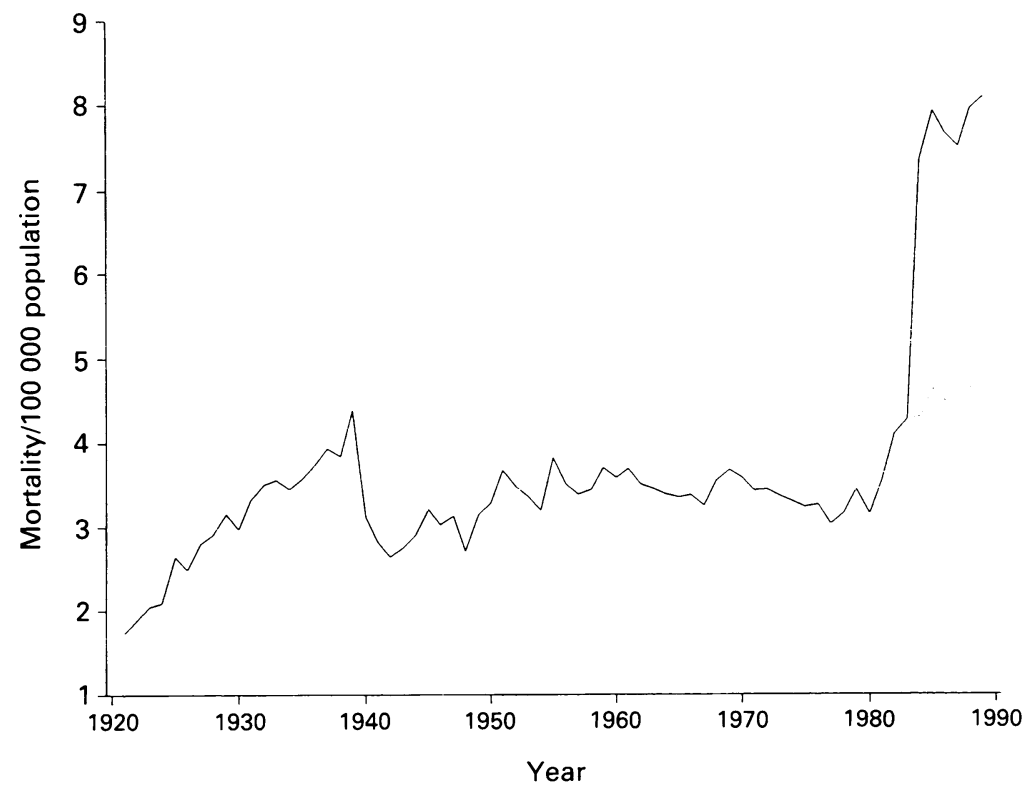

Figure 1 Crude mortality rate for Parkinson's disease in England and Wales. To allow for the change in classification in 1984, the OPCS 1984 correction factor has been applied to all subsequent years (dotted line).

\section{Results}

The crude mortality rate for Parkinson's disease in England and Wales steadily increased from 1921 to 1940 (fig 1). The fall in 1940 coincided with the adoption of ICD-5 and the abandoning of the "joint cause rules" by which chronic conditions such as Parkinson's disease were selected as the cause of death when more than one cause was given, rather than the acute terminal condition. Between 1940 and 1960, mortality continued to rise at a similar rate to that before the change in death certification. Mortality remained static from 1960 to 1980 but increased in the early 1980s. The rise in 1984 coincided with the adoption of the WHO rule 3 by which chronic conditions recorded on the certificate

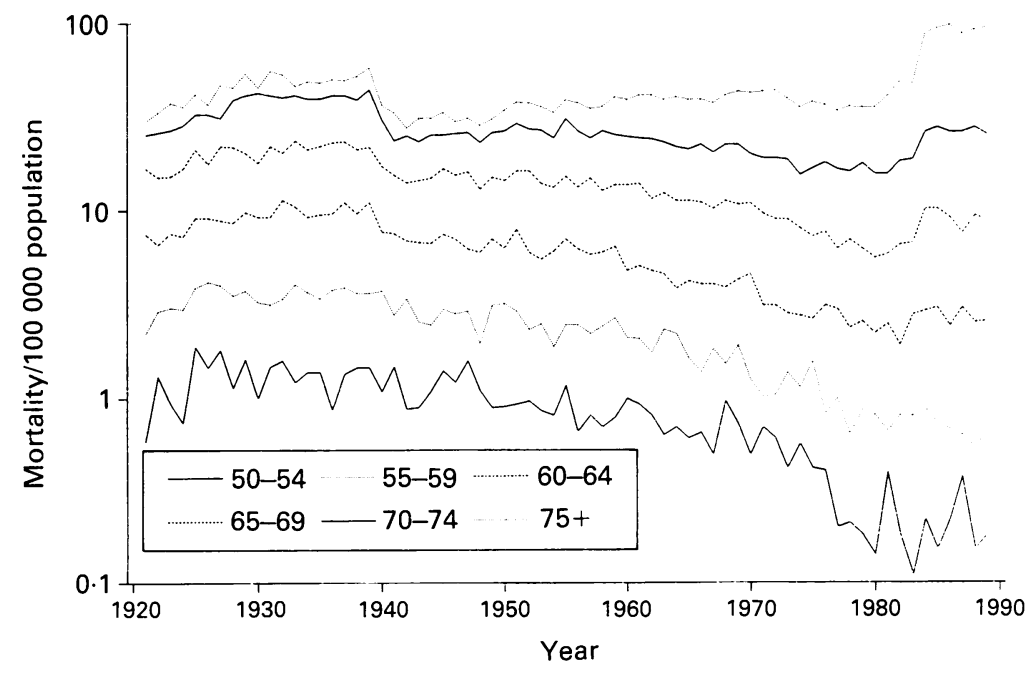

Figure 2 Age-specific mortality rates for Parkinson's disease in England and Wales. Note logarithmic scale for mortality. were taken as the cause of death if they were likely to have led to the terminal illness. If this is allowed for by applying the OPCS correction factor for 1984 to successive years, the dramatic rise disappears and is replaced by a gradual increment in line with that seen in other decades. By returning to the pre1940 method of certification, it appears that mortality has risen by $300 \%$ from 1921 to 1989. The crude mortality was similar in men and women apart from a more pronounced fall from 1970 to 1980 in women.

Age-specific mortality rates increased in all age groups from 1921 to 1940 (fig 2) but fell in those over 60 years with reclassification in 1940. There followed a sustained fall to 1980 in groups below 70 years. For those aged 70-74 years, mortality increased initially during this period but then fell. A sustained rise was seen in those aged over 75 years which was attenuated in the 1970s. The fall in younger groups may also have accelerated in the 1970 s.

Mortality increased in all groups in the 1980 s before further increases followed the change in death certification in 1984. These trends were similar in men and women.

The mortality rate standardised to the population structure and mortality of 1921 showed a steep rise to 1940 (fig 3). The SMR then remained static until the period 1960 to 1980 in which it fell. In the early 1980 s, SMR increased in both sexes but more so after 1984 , so that levels in men were comparable to pre-1940 levels; a lesser increment was seen in female mortality.

Cohort analysis of mortality by birth year is confounded by changes in death certification (table 1). For the period of uniform classification 1940-1983, mortality at ages below 70 years fell with successive birth cohorts, whereas above 75 years mortality remained stable. A fall in mortality is also seen using pre-1940 and post-1983 data for ages 60-64 and 70-74 (in parentheses in table 1). Identical trends were seen in men and women.

\section{Discussion}

The interpretation of trends in mortality statistics is fraught with difficulties for a number of reasons. Inaccurate death certification is a particular problem. In the case of Parkinson's disease, idiopathic Parkinson's disease can be confused with other common causes of Parkinsonism, such as a multiple infarct state or the multiple system degenerations (for example, progressive supranuclear palsy and striatonigral degeneration) leading to overdiagnosis. Indeed, idiopathic Parkinson's disease itself may have more than one pathogenesis.

A more common problem is omission of the condition from the death certificate altogether, the terminal event being recorded as the cause of death (for example, bronchopneumonia). Parkinson's disease was recorded as the primary cause of death in between 8 and $85 \%$ of cases in two reviews taking data 


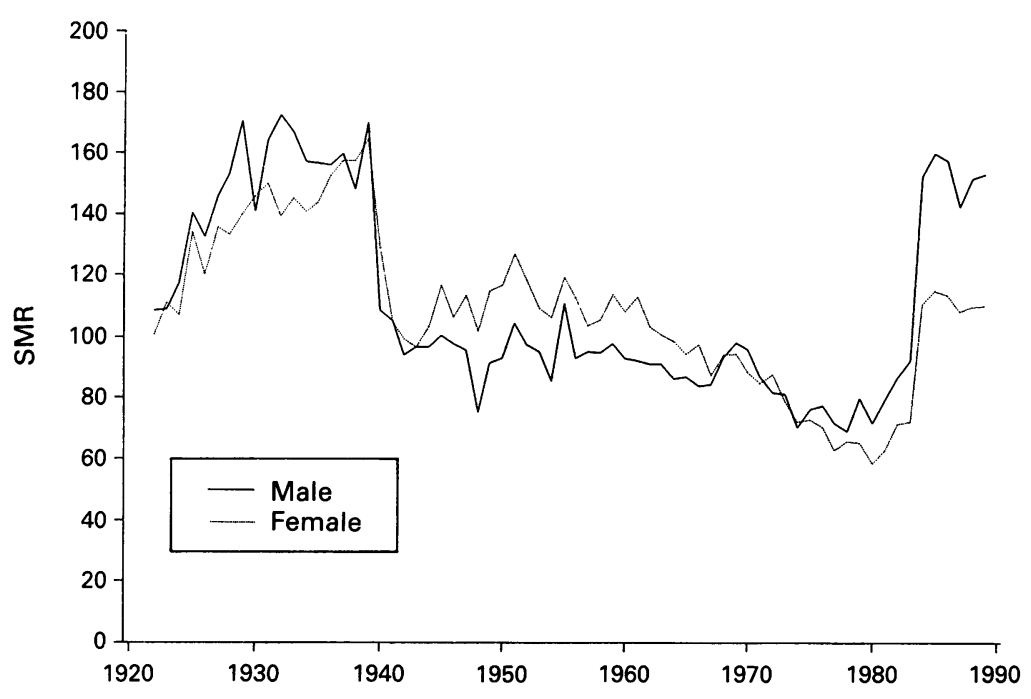

Figure 3 Standardised mortality ratio (SMR) for Parkinson's disease in England and Wales. SMR in reference year 1921 equals 100. For method of calculation see text.

from several countries..$^{11}$ In a study of death certification in Rochester, Minnesota only $20 \%$ of Parkinsonian patients had the diagnosis recorded on the certificate. ${ }^{10}$

Changes in the way death certificates are interpreted and coded pose further problems. This is typified here by the artefactual fall in mortality in 1940 when the terminal event was taken as the cause of death (that is, part la on United Kingdom certificates) and by the rise in 1984 when WHO rule 3 was adopted, thus reverting back to the old system of taking major chronic conditions as the cause of death in certain circumstances.

Interpretation is also made difficult by multiple confounding variables acting at the same time. Thus the increase in the elderly population over the period of the current study will lead to an increase in deaths from idiopathic Parkinson's disease which has a higher prevalence in this age group. By contrast, the introduction of levodopa in the 1970 s will cause a reduction in mortality. Adequate allowances must be made for all of the above difficulties when attempting to draw any conclusions from these data.

The overall trend in crude mortality from 1921 to 1989 suggests that deaths from

Table 1 Age-specific mortality from Parkinson's disease by birth cohort for England and Wales, 1921-1989

\begin{tabular}{|c|c|c|c|c|c|c|c|c|}
\hline \multirow[b]{2}{*}{ Age at death } & \multirow[b]{2}{*}{1855} & \multicolumn{4}{|c|}{ Mortality/100 000 population/birth year } & \multirow[b]{2}{*}{1905} & \multirow[b]{2}{*}{1915} & \multirow[b]{2}{*}{1925} \\
\hline & & 1865 & 1875 & 1885 & 1895 & & & \\
\hline $\begin{array}{l}50-54 \\
55-59 \\
60-64 \\
65-69 \\
70-74 \\
75-79 \\
80-84\end{array}$ & $\begin{array}{l}(35 \cdot 20) \\
(52 \cdot 18)\end{array}$ & $\begin{array}{c}(9.00) \\
(20.94) \\
(41.01) \\
31 \cdot 01 \\
32.74\end{array}$ & $\begin{array}{c}(1.56) \\
(3.46) \\
(10.05) \\
15.07 \\
25.21 \\
36.72 \\
40.59\end{array}$ & $\begin{array}{c}(1 \cdot 29) \\
2.95 \\
6 \cdot 68 \\
14.70 \\
26.58 \\
37.22 \\
43.49\end{array}$ & $\begin{array}{r}1 \cdot 23 \\
2.53 \\
6 \cdot 25 \\
12.38 \\
21 \cdot 63 \\
34 \cdot 78 \\
40 \cdot 92\end{array}$ & $\begin{array}{c}0.81 \\
2.07 \\
4.07 \\
9 \cdot 21 \\
16.91 \\
38.57 \\
(105.81)\end{array}$ & $\begin{array}{r}0.68 \\
1.18 \\
2.70 \\
6.93 \\
(26.43)\end{array}$ & $\begin{array}{c}0.28 \\
0.78 \\
(2.68)\end{array}$ \\
\hline
\end{tabular}

*Mortality rate expressed as the mean of the five age-specific rates.

Numbers in parentheses refer to years of death pre-1940 and post-1984 when classification of Numbers in parentheses refer to years of death pre-1940 and
death included chronic diseases such as Parkinson's disease.
Parkinson's disease have risen by $300 \%$ (fig 1). However, if changes in the age structure of the population are allowed for by applying age-specific mortality rates to the population of 1921 and calculating a standardised mortality ratio (fig 3 ) then the increase is reduced to only $20 \%$ in women and $60 \%$ in men. This less marked rise may be consistent with improvements in the diagnosis of the condition and in the quality of death certification rather than any increase in the aetiological factor(s) responsible for the disease. Nevertheless, the scale of the increment in Parkinson's disease mortality due to the changing age structure of the population is considerable and has wide ranging implications with regard to the provision of health care in the future.

Commencing around 1940, age-specific death rates showed a sustained fall in mortality in younger age groups compared with an increase in those over 75 years (fig 2). Identical trends have been reported from United States. ${ }^{1213}$ Analysis of mortality by birth cohort is more complex. Taking the peak age of occurrence of encephalitis lethargica as between 20 and 40 years and the dates of the major outbreaks between 1918 and $1926,{ }^{5}$ the possible birth years of affected patients extend from 1878 to 1906 . These birth years cover the majority of patients in table 1 so it is unlikely that a clear peak in one birth year will occur. Nevertheless, a decline in deaths at younger ages with successive birth cohorts did occur in keeping with age-specific mortality data. This continues to be consistent with the two disease hypothesis of Duvoisin and colleagues. ${ }^{2}$ A group of younger patients who developed a Parkinsonian syndrome long after exposure to encephalitis lethargica continue to die out. This leaves an increasing number of cases of idiopathic Parkinson's disease or paralysis agitans.

Although these two groups could not be differentiated clinically, the pathological findings in each are characteristic. Thus, Jellinger found the frequency of post-encephalitic Parkinsonism to be $12 \%$ in his unselected series of 110 necropsies in patients with Parkinson's disease between 1957 and $1970 .{ }^{14}$ This compares with only $4 \%$ in his 1971-84 series of 350 cases. ${ }^{14}$ In addition to a fall in the number of post-encephalitic cases over recent years, Forno describes such cases in which there was no history of encephalitis lethargica. ${ }^{15}$ This suggests that subclinical infection played a part in the nigral damage in these cases. This raises the theory once again that some, perhaps most, cases of idiopathic Parkinson's disease have a similar viral pathogenesis and that the viral illness may be subclinical. It has even been suggested that exposure to influenza virus in utero may be responsible for nigral damage in view of peaks in patients birth years coinciding with epidemics of influenza. ${ }^{16}$

In the United States and Scandinavian countries, mortality from Parkinson's disease increased at all ages in the early $1980 \mathrm{~s}^{6-10}$ 
This increment occurred over several years making it unlikely that a sudden change in the classification of mortality by adoption of WHO rule 3 was responsible. A similar trend occurred in the United Kingdom before the change in classification in 1984 but, using the OPCS correction factor post-1984, the gradient of the increase in mortality seems to have returned to its pre-1960 level (fig 1). The increase in the early 1980 s followed a small fall in mortality in the 1970 s in most age groups but more clearly seen in those over 65 years. This corresponds to the introduction of levodopa preparations which probably delayed the deaths of many elderly patients who finally succumbed in the early 1980 s. Kurtzke and colleagues concluded that levodopa had increased the mean survival in Parkinson's disease at all ages by five years in the United States and Scandinavia. ${ }^{610}$ This is compatible with the fall in observed to expected mortality in Parkinsonian patients from 2.9 before levodopa therapy $(1949-64)^{17}$ to $1 \cdot 2$ following its introduction (1970-82), ${ }^{18}$ although this has not been seen in all such studies. ${ }^{19}$

In conclusion, Parkinson's disease mortality between 1960 and 1989 in England and Wales must be explained by a number of variables. Throughout this period, there has been a progressive rise in mortality because of the ageing of the population. The large group of younger patients with post-encephalitic Parkinsonism largely died out during these decades leading to the plateau in the mortality curve. Levodopa deferred the deaths of an increasing proportion of patients with a progressive reduction in overall mortality in the 1970s. However, these patients died a mean of five years later leading to the abrupt rise in mortality in the early 1980s. The attenuating effects of the latter two variables have now waned and the steady rise in the mid to late
1980 s is once again due to the changing age structure of the population.

I thank Dr AJ Franks and Dr EGS Spokes for their critical reading of the manuscript.

1 Poskanzer DC, Schwab RS. Cohort analysis of Parkinson's disease: evidence for a single etiology related to subclinical infection about 1920. $\mathcal{F}$ Chronic Dis 1963;16:961-73.

2 Duvoisin RC, Yahr MD, Schweitzer MD, et al. Parkinsonism before and since the epidemic of encephalitis lethargica. Arch Neurol 1963;9:232-6.

3 Parkinson J. An essay on the shaking palsy. London: Whittingham and Rowland, 1817.

4 Duvoisin RC, Schweitzer MD. Paralysis agitans mortality in England and Wales, 1855-1962. Br ₹ Prev Soc Med 1966;20:27-33.

5 Marmot MG. Mortality and Parkinson's disease. In: Clifford Rose F, Capildeo R, eds. Research progress in Clifford Rose F, Capildeo R, eds. Research pro
Parkinson's disease. London: Pitman, 1981:9-16.

6 Kurtzke JF, Murphy FM. The changing patterns of death rates in parkinsonism. Neurology 1990;40:42-49.

7 Riggs JE. Longitudinal Gompertzian analysis of Parkinson's disease mortality in the US, 1955-1986: the dramatic increase in overall mortality since 1980 is the natural consequence of deterministic mortality dynamics. Mech Ageing Dev 1990;55:221-33.

8 Flaten TP. Changing mortality from Parkinson's disease. Neurology 1991;41:329-30.

9 Kurtzke JF, Flaten TP, Murphy FM. Death rates from Parkinson's disease in Norway reflect increased survival. Neurology 1991;41:1665-7.

10 Williams GR. Morbidity and mortality with parkinsonism.

$\mathcal{F}$ Neurosurg 1966;24:138-43.
11 Kessler II. Parkinson's disease in epidemiological perspective. Adv Neurol 1978;19:355-84.

12 Lilenfeld DE, Chan E, Ehland J, et al. Two decades of increasing mortality from Parkinson's disease among the US elderly. Arch Neurol 1990;47:731-4.

13 Treves TA. Parkinson's disease mortality. Adv Neurol 1990;53:411-5.

14 Jellinger $K$. Pathology of parkinsonism. In: Fahn S, Marsden CD, Jenner P, Teychenne P, eds. Recent developments in Parkinson's disease. New York: Raven Press, 1986:33-66.

15 Forno LS. Pathology of Parkinson's disease. In: Marsden $\mathrm{CD}$ and Fahn S, eds. Movement disorders. London: Butterworth, 1982:25-40.

16 Mattock C, Marmot M, Stern G. Could Parkinson's disease follow intra-uterine influenza?: a speculative disease follow intra-uterine influenza?: a speculative
hypothesis. $f$ Neurol Neurosurg Psychiatry 1988;51:

17 Hoehn MM, Yahr MD. Parkinsonism: onset, progression, and mortality. Neurology 1967;17:427-42.

18 Hoehn MM. Parkinson's disease: progression and mortality. Adv Neurol 1986;45:457-61.

19 Curtis L, Lees AJ, Stern GM, Marmot MG. Effect of L-dopa on the course of Parkinson's disease. Lancet 1984;ii:211-2 